\title{
The Role of Social Media in Developing Social Responsibility and Political Awareness of Jordanian Youth
}

\author{
Amani G. Jarrar ${ }^{1} \&$ Muwafaq Abu Hammud ${ }^{2}$ \\ Department of Development Studies, Faculty of Arts, Philadelphia University \\ Correspondence: Amani G. Jarrar. Tel: 96-27-9552-2401. E-mail: aj8infinity@gmail.com
}

Received: December 4, 2017

Accepted: December 13, 2017

Online Published: February 26, 2018

doi:10.5539/ass.v14n3p25

URL: https://doi.org/10.5539/ass.v14n3p25

\begin{abstract}
This study aimed at exploring the role of social media in developing social responsibility and political awareness of the Jordanian youth, where the researcher adopted the descriptive analytical methodology, by developing a specific questionnaire as a study tool. The study sample consisted of (200) students from Philadelphia University with all education levels for the academic years (2016-2017). The results showed that there are statistically significant differences at the level of significance $(\alpha=0.05)$ of the role of social media in developing social responsibility and political awareness of the Jordanian youth.
\end{abstract}

Keywords: social media, social responsibility, political awareness, Jordan, youth

\section{Introduction}

The world is undergoing huge changes in information technology, and this is compelling a clear effect on the political, economic, social and cultural environment, particularly in Jordan. Social websites are presently known as current online networking that witness a dynamic development, and initially, they were only a restricted and tight virtual society which subsequently developed to turn from a printed instructive instrument to a varying media device that influences the choices and reactions of individuals. The larger part of population has managed this sort of innovation. (Husein, Al-Sukkar, Salah, \& Jaradat, 2013).

We are experiencing a new phase of dynamic movement of Social networking; particularly Facebook, Twitter, LinkedIn, etc. appeared. It was initially a virtual society on a narrow and limited scale, and then gradually increased over time; it developed from an informational written text to an audio-visual tool affecting decisions-taking (Hart, 2008).

Social activities reflect the need of young people in particular. They show youth talents, potentials and tendencies in various fields of cultural and social activities. Development can never take place without the engagement and preparation of youth; they are a tool for development. Community has the intrinsic capacity to grow and develop only through young generation's creativity, professional and technical skills, and their sense of responsibility (Collins \& Halverson, 2010).

Youth represent an age group with an important role in community, filling it with hope to build our future nation. They have the ability and vitality to work and change for the better serving society, through using some guided and thoughtful sites of social media, using their social skills, experiences and social capacities that exist and develop with a sense of social responsibility that may help them to be more productive.

As social media have contributed to activating youth participation, helping in achieving the desire and interests of each common group, so that the young generation has a role in networking, advocacy, lobbying, interaction and even may help in influencing leaders, and in achieving social responsibility if they are well invested, and directed (Sabagh, 2010).

Social media plays an important role in educating young people training them on practicing social networking habits as an important tool of social change. The social and educational institutions are interested in developing youth programs and activities, training them how to benefit of time. The educational process is useful for building youth personalities, raising the spirit of social responsibility and self-esteem, making them able to under-take responsibilities (Laker, 2002).

Young people use media and social institutions, reflecting their needs through modern technology, showing their 
behavior and personality patterns; so that youth behavior is a process with mental, psychological, social, or environmental components affected by different conditions, attitudes, social and cultural elements. It is mainly based on the interaction between young individuals, groups and communities. Youth develop a sense of responsibility and self-reliance through these processes and activities they engage in with other groups, through social media networking, learning types of behavior, and gaining positive experiences through this interaction (Holmes \& O'loughlin, 2014).

\subsection{Problem Statement and Study Questions}

Social responsibility is associated to human beings as such. Social networking plays an important role in the development of social responsibility and political awareness through youth groups creating web sites and social pages adopting social issues that are at the center of their interests, publishing and defending them, using communication skills, advocacy and pressure techniques. Youth is considered a critical factor in the progress of society. The problem of the study may be manifested in the following questions: What is the impact of the use of social media in the development of social responsibility and political awareness among the youth?

\subsection{Importance of the Study}

The study importance derives from the nature of youth in our society and its role. This group is an important and influential human force in our society. Such studies will pave the way for other studies adding more influential variables in the study, and thus contributing to the accumulation research on social media, and social / political responsibility.

\subsection{Terminology}

Social Media: Forms of electronic communication (such as websites for social networking) through which users create online communities to share information, ideas, personal messages, and other content (such as videos). It is a system of electronic networks, linked through electronic social system (Sabagh, 2010).

Social responsibility: It is an ethical framework suggesting that an entity has an obligation to act for the benefit of society. Social responsibility is an individual duty to maintain balance between economy and other systems. It is the responsibility towards family, friends and homeland, through positive participation in solving society problems trying to achieve the general goals using all available means (Awad, 2015).

\subsection{Study Hypotheses}

Regarding the problem of the study, and its questions, the researchers has adopted the following hypotheses:

Major hypothesis

H0: At the level of significance $(\alpha \leq 0.05)$, there will be no statistically significant differences of the role of social media in developing social responsibility and political awareness of the Jordanian youth.

Sub-hypotheses:

The ramifications of the major hypothesis are the following sub-hypotheses:

H01: At the level of significance $(\alpha \leq 0.05)$, there will be no statistically significant differences of the role of social media in developing social responsibility of the Jordanian youth upon gender and specialization.

H02: There will be no statistically significant differences at the level of significance $(\alpha \leq 0.05)$ of the role of social media in developing political awareness of the Jordanian youth upon gender and specialization

H03: There will be no statistically significant differences at the level of significance $(\alpha \leq 0.05)$ of the role of social media in developing social responsibility of the Jordanian youth upon education level.

H04: At the level of significance $(\alpha \leq 0.05)$, there will be no statistically significant differences of the role of social media in developing political awareness of the Jordanian youth upon education level.

H05: At the level of significance $(\alpha \leq 0.05)$, there will be no statistically significant differences of the role of social media in developing social responsibility of the Jordanian youth upon specialization.

H05: At the level of significance $(\alpha \leq 0.05)$, there will be no statistically significant differences of the role of social media in developing political awareness of the Jordanian youth upon specialization.

\subsection{Literature Review and Previous Studies}

From Facebook, YouTube, Twitter, and websites, news can be delivered to 20 million watchers overnight. The viral idea of this social media empowers people to communicate their convictions, wishes or interests (Maguth, 2013). 
The "information age" or "computerized age" influences the region of ICT, overcoming impediments of time and space in data sharing and systems administration. This does not just influence how we associate with other individuals and how we work together, yet additionally it influences how we interface in the political circle. In that specific situation, online networking can be considered as a potential apparatus for encouraging the social contract between the people and the state (Castells, 2011).

For instance, government can possibly utilize social media platforms to request criticism on its approaches and political activities, while people can utilize similar steps to express their outrage, dissatisfactions or acknowledgment of whatever activities government is embracing. Online devices and web-based social networking can open new roads for interest. Social media platforms can enable nationals to investigate better approaches for participation, they can open chances to activating individuals around a typical reason or for affecting the society on particular issues. Social media that is web-based social networking differs from conventional media in providing an open space, possibly giving each individual a way to specifically connect with others (Golbeck, 2005).

Social media and networks are some of the most prominent manifestations of new media, which helped in internet revolution; it is based on new technologies such as forums, blogs and social networking programs (Ibrahim, 2009).

Social interaction, which is a communicative process is considered by psychologists and sociologists as the basis of public relations between individuals. Thus the core of the communicative process consists of: Cognitive, and behavioral processes between the connected parties. The basic idea of social networking was initially based on achieving interaction, it developed into social aspects in various political, economic sectors (Abu Ya'qub, 2015).

The idea of social network sites is a social term that makes ones' essential needs of individuals to form their lives. The human instinct enables the individuals to communicate with each other (Safko, 2010).

Social network sites are international websites associated with many gadgets round the world to shape a gathering of huge systems that exchange immense and persistently created data in a split of second among the distinctive nations of the world (Al-Sharhan, 2003).

The term was additionally defined by Al-Shahri (2009) as an arrangement of electronic systems that enable a member to set up his/her own particular site and to share it through an electronic social framework to different individuals from different interests and hobbies. Social networks were defined originally by John Barnz in 1954, who is well -known as a specialist at London University (Serrat, 2009).

Users are enabled to interface with companions through discussions, and pictures social network sites. Dyrli and Kinnman (1996) expressed that the web helps creating thinking aptitudes and innovative intuition.

Any devoted community members are expressed as providing contribution for the correction and rehabilitation of circumstances within the community are social responsibilities. Hence, individuals must implement their social responsibilities by investing in the issues (hunger and poor nutrition, poverty, unemployment, employment possibilities in the orientation of disabled persons, prevention of violence, protection of environment, and developing consciousness and awareness in environment issues, etc.) by providing support for the solution of these issues (Göksu, 2014).

Social media is more required due to giving probability for instant information exchange. Since, social media channels, as compared to conventional media, is significantly faster and intuitive. Despite the fact that they do not have fast and rich feedback possibilities of face to face and one-to-one communication, social media is able to create a high social readiness (Köseoğlu \& Köker, 2014).

Political awareness in the online political discussion is a significant type of political participation that has been facilitated by the rise of social media (Molaei, 2014). Valuable political discourse requires several preconditions; the most important one is reasonable argument and justification. In this regard, political awareness is a significant factor required for offering convincing arguments.

With their user content features; social media have significantly changed people's modes of social and political participation. These participatory media have provided a big opportunity for individuals' social and political awareness. They have also posed several challenges to people's constructive political engagement. Several studies have referred to the positive role of the Internet and social media for political awareness because they facilitate citizens' social and political engagement; others proposed the challenges that are provided by the Internet and social media. It is important to highlight that each of these opinions may be correct since these platforms may be used both in constructive and an unconstructive manner due to their nature of user generated content (Molaei, 2017). 


\subsection{Previous Studies}

A number of studies have examined the impact of the use of social media on the personality of young people. Ben Wargala's study (2015), which investigated the role of social networks in the development of political and social awareness among Arab youth by analyzing the role played by the new type of media, especially social networks, in developing political and social awareness among Arab youth. Social networks play political, economic and social roles in people's lives.

The study of Ghazal (2014) entitled "The impact of social media on the development of political awareness among university students." aimed at revealing the impact of social networking and social media on development of political awareness. The questionnaire was used to collect data from the respondents. The study was divided into theoretical and practical aspects, in which the hypotheses of the questionnaire were investigated. The first is the use of social networking social media, and the second is the use of social media by students, the third is the importance of students' political awareness. The study found the following results: The majority of the respondents spend more than three hours on internet and social media, and most prefer to comment and chat in the first place, so as to express their opinions freely. Most of the respondents use the social media to communicate with friends and family as well as education, and the results show that the sites develop political awareness by opening a political debate within the virtual community.

The study of Hafez (2011) which is titled "University Youth Communication through Social Network Sites" conducted an investigation that went for recognizing the genuine thought processes of correspondence among university studies through informal community locales. The examination confirmed that such correspondence is viewed as a social wonder more than being a need made by present day innovation.

A study by Karbnsky Aren (2010) entitled "Facebook and the Technology Revolution", also aimed at identifying the impact of using "Facebook" on university students' achievement, and the study was applied to (219) university students, where the results showed that University students who are addicted to Internet and Facebook, and who have larger social network are lower in achievement than those who do not use it, and the results also showed that the more time spent by the university student to browse this site, the lower their grades are in their attended examinations, so that the people who spend more time on the Internet devote a shorter time to study, noting that each generation has certain interests, and that this site allows the user to "chat", and express their opinions on many things, and even make new friends. Thus, college students admitted that their addiction to Facebook had a negative impact on their education.

\section{Methods and Procedures}

\subsection{Study Population and Study Sample}

The population of the study consists of all the students in Philadelphia University for the academic year (2016-2017), and the sample of study was randomly chosen with the size of 200 students of all faculties in the university.

\subsection{Descriptive Characteristics of the Study Sample}

\subsubsection{Gender}

The distribution of the study sample of Philadelphia University students for the academic year (2016-2017) upon gender is shown in Figure 1.

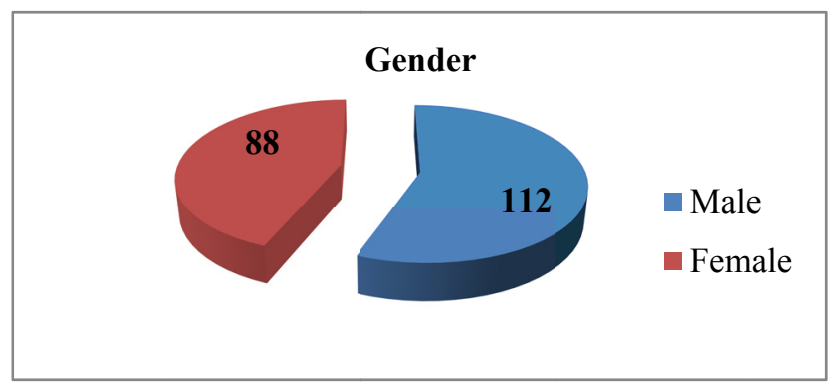

Figure 1. Distribution of the study sample of the Philadelphia University students for the academic year (2016-2017) upon gender

\subsubsection{Education Level}

The distribution of the study sample of the Philadelphia University students for the academic year (2016-2017) upon the education level is shown in Figure 2. 


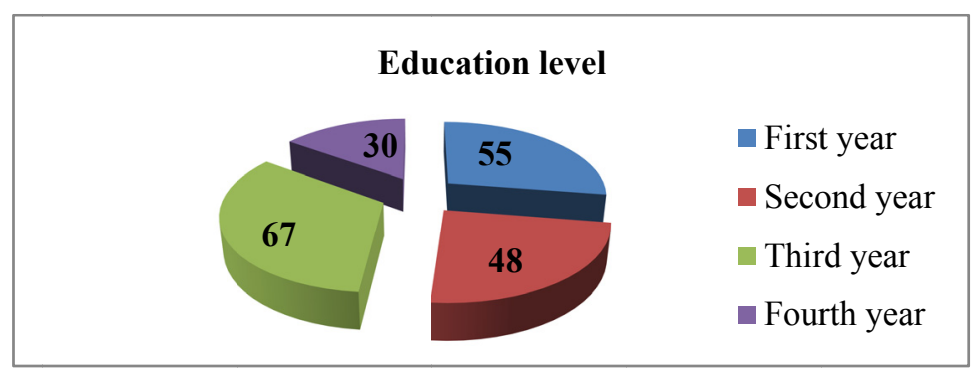

Figure 2. Distribution of the study sample of Philadelphia University students for the academic year (2016-2017) upon the education level

\subsubsection{Specialization}

The distribution of the study sample of Philadelphia University students for the academic year (2016-2017) upon specialization is shown in Figure 3.

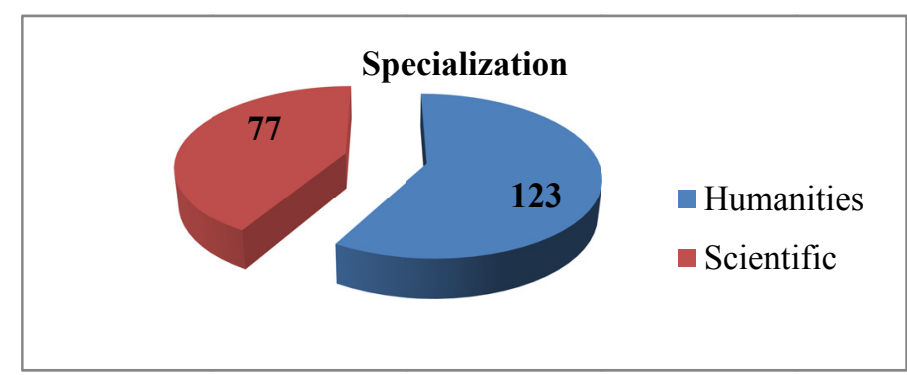

Figure 3. Distribution of the study sample of Philadelphia University students for the academic year (2016-2017) upon specialization

\subsection{Study Tool}

After examining the literature and theoretical studies relevant to the subject of this study; the study relied mainly on a self-managed questionnaire designed and prepared by the researchers after reviewing periodicals, books or other references, the questionnaire was formed in three parts and as follows:

Part I: Includes information related to the respondents of Philadelphia University students including the study of demographic variables (gender, education level and specialization).

Part II: Includes (20) paragraphs related to the measurement of the social responsibility with its four perspectives (self-responsibility, intellectual and moral responsibility, collective responsibility and national responsibility).

Part III: which included (10) paragraphs measuring the political awareness among the students of Philadelphia University.

\subsection{Questionnaire Validity}

For ensuring the validity of the study tool; the questionnaire was reviewed by a faculty members of the Jordanian universities in the same field of this research, for identifying the suitability of the questionnaire for the goals to be achieved, and by retrieving all suggestions, all the necessary adjustments on the paragraphs of the questionnaires were made, by deleting, adding some paragraphs, and by rephrasing others.

\subsection{Questionnaire Reliability}

The researchers used the internal consistency coefficient $(\alpha)$ according to the alpha Cronbach equation for ensuring the reliability of the questionnaire, and the value of $(\alpha) 94 \%$, which is very high when compared with the minimum acceptable of $65 \%$.

\section{Study Results and Findings}

\subsection{Trends Toward Social Responsibility}

\subsubsection{Trends Toward Self-responsibility Perspective}

Self-responsibility variable is measured in paragraphs (1-5), as shown in table (1), and the arithmetical means for answers of the study sample ranged between $(4.01-3.44)$, and the standard deviations ranged between $(0.778$ $0.811)$. 
All of these arithmetic means show the approval of the study sample on the paragraphs that measure self-responsibility perspective variable, since all the arithmetic means are greater than the default means.

It is also noted that the paragraph, which states "People who desire enjoying the benefits of social networking are expected to create a profile of themselves on these sites", they had the highest approval grades; as its arithmetic means was (4.01) and its standard deviation was (0.778), while the paragraph, which states "Self-responsibility approach usually requires an exploratory conversation in which the conversationalist asks the person to identify a problem they personally experience" had the lowest approval grades; as its arithmetic means was (3.44), and its standard deviation was (0.811).

Overall, the general average of the arithmetic means for the answers of the respondents is equivalent to (3.75) and the standard deviation is equivalent to (0.795), which indicates the approval of the respondents upon the scale of these paragraphs was high, and that their attitudes were positive.

Table 1. Arithmetic means and standard deviations for the members of the study sample answers measuring the attitudes towards self-responsibility perspective.

\begin{tabular}{|c|c|c|c|c|c|}
\hline $\mathrm{NO}$ & Statement & A M & S D & Rank & Grade \\
\hline 1 & $\begin{array}{l}\text { Self-responsibility approach usually requires an exploratory conversation in } \\
\text { which the conversationalist asks the person to identify a problem they } \\
\text { personally experience }\end{array}$ & 3.44 & 0.811 & 5 & Medium \\
\hline 2 & $\begin{array}{l}\text { People who desire enjoying the benefits of social networking are expected to } \\
\text { create a profile of themselves on these sites }\end{array}$ & 4.01 & 0.778 & 1 & High \\
\hline 3 & $\begin{array}{l}\text { Social media is a positive development tool, but users should make sure that } \\
\text { they use it for the right reasons to avoid problems }\end{array}$ & 3.87 & 0.791 & 2 & High \\
\hline 4 & $\begin{array}{l}\text { We're taking seriously the opportunity that social media provides, and the risks } \\
\text { that it entails }\end{array}$ & 3.75 & 0.801 & 3 & High \\
\hline \multirow[t]{2}{*}{5} & $\begin{array}{l}\text { Social media platforms enable us to expand and enrich our personal networks in } \\
\text { new ways }\end{array}$ & 3.69 & 0.799 & 4 & High \\
\hline & General average & 3.75 & 0.795 & - & High \\
\hline
\end{tabular}

(AM) is the arithmetic means, (SD) is the standard deviation

\subsection{Trends Toward the Intellectual and Moral Responsibility Perspective}

The intellectual and moral responsibility perspective variable is measured in paragraphs (6-10), as shown in table (2), and that the arithmetical means for answers of the study sample ranged between $(3.82-2.91)$, and the standard deviations ranged between (1.021- 0.776).

All of these arithmetic means show the approval of the study sample on the paragraphs that measure the intellectual and moral responsibility perspective variable, since all the arithmetic means are greater than the default means.

Also noted that the paragraph, which states "The network does not raise even the most basic requirements for age, cultural, intellectual and moral level of the user" had the highest approval grades; as its arithmetic means was (3.82) and its standard deviation was (0.776), while the paragraph, which states "Cyberethics is based on common sense and prudence, and it also includes the commandments of online behavior" had the lowest approval grades; as its arithmetic means was (2.91) and its standard deviation was (1.021).

Overall, the general average of the arithmetic means for the answers of the respondents is equivalent to (3.52) and the standard deviation is equivalent to (0.848), which indicates the approval of the respondents upon the scale of these paragraphs was Medium, and that their attitudes were positive.

Table 2. Arithmetic means and standard deviations for the members of the study sample answers measuring the attitudes towards the intellectual and moral responsibility perspective.

\begin{tabular}{|c|c|c|c|c|c|}
\hline NO & Statement & A M & S D & Rank & Grade \\
\hline 6 & $\begin{array}{l}\text { Global opportunity to engage many cultures, as well as sub- and counterculture } \\
\text { in the dialog that will lead to spreading of values }\end{array}$ & 3.62 & 0.801 & 3 & Medium \\
\hline 7 & $\begin{array}{l}\text { There is a number of important features of the Web, which inevitably turn into a } \\
\text { crisis in the sphere of public morality }\end{array}$ & 3.50 & 0.865 & 4 & Medium \\
\hline
\end{tabular}


8

Cyberethics is based on common sense and prudence, and also includes the commandments of online behavior

9

Network does not raise even the most basic requirements for age, cultural, intellectual and moral level of the user

The essential features of network space allowed millions of people initially feel

10 the possibility of broad freedom, including freedom from social control and moral requirements
$2.91 \quad 1.021 \quad 5 \quad$ Medium

$3.82 \quad 0.776 \quad 1 \quad$ High

$3.73 \quad 0.778 \quad 2 \quad$ High

General average

$3.52 \quad 0.848 \quad-$

Medium

(AM) is the arithmetic means, (SD) is the standard deviation

\subsection{Trends Toward the Collective Responsibility Perspective}

The collective responsibility perspective variable is measured in paragraphs (11-15), as illustrated in table (3), and that the arithmetical means for answers of the study sample ranged between (3.88-2.99), and the standard deviations ranged between (0.895- 0.765).

All of these arithmetic means show the approval of the study sample on the paragraphs that measure the collective responsibility perspective variable, since all the arithmetic means are greater than the default means.

Also noted that the paragraph, which states "Individualism vs. collectivism is debated within social media networks environments very frequently as well" had the highest approval grades; as its arithmetic means was (3.88) and its standard deviation was (0.765), while the paragraph, which states "There are no easy answers as to when, we as a society should lean either towards individualism or collectivism" had the lowest approval grades; as its arithmetic means was (2.99) and its standard deviation was (0.895).

Overall, the general average of the arithmetic means for the answers of the respondents is equivalent to (3.52) and the standard deviation is equivalent to (0.842), which indicates the approval of the respondents upon the scale of these paragraphs was Medium, and that their attitudes were positive.

Table 3. Arithmetic means and standard deviations for the members of the study sample answers measuring the attitudes towards the collective responsibility perspective.

\begin{tabular}{|c|c|c|c|c|c|}
\hline $\mathrm{NO}$ & Statement & A M & S D & Rank & Grade \\
\hline 11 & $\begin{array}{l}\text { Gathering small efforts enabled by social media to culminate into collective } \\
\text { action, could be a great addition to student's social responsibility activities }\end{array}$ & 3.69 & 0.792 & 2 & High \\
\hline 12 & $\begin{array}{l}\text { We're collectively responsible for social media platforms, clicks and retweets of } \\
\text { inspirational stories and the use of technology by people with disabilities }\end{array}$ & 3.41 & 0.876 & 4 & Medium \\
\hline 13 & $\begin{array}{l}\text { Our society which is made up of many different and overlapping groups forces } \\
\text { us to consider if we are collectively responsible for the welfare of those who } \\
\text { reside within our society }\end{array}$ & 3.64 & 0.881 & 3 & Medium \\
\hline 14 & $\begin{array}{l}\text { There are no easy answers as to when we as society should lean either towards } \\
\text { individualism or collectivism }\end{array}$ & 2.99 & 0.895 & 5 & Medium \\
\hline 15 & $\begin{array}{l}\text { Individualism vs. collectivism is debated within social media networks } \\
\text { environments very frequently as well }\end{array}$ & 3.88 & 0.765 & 1 & High \\
\hline & General average & 3.52 & 0.842 & - & Medium \\
\hline
\end{tabular}

(AM) is the arithmetic means, (SD) is the standard deviation

\subsection{Trends Toward the National Responsibility Perspective}

The national responsibility perspective variable is measured in paragraphs (16-20), as illustrated in table (4), and that the arithmetical means for answers of the study sample ranged between (3.98- 3.11), and the standard deviations ranged between (0.898-0.734).

All of these arithmetic means show the approval of the study sample on the paragraphs that measure the national responsibility perspective variable, since all the arithmetic means are greater than the default mean.

Also noted that the paragraph, which states "Social media highlighted our international experiences in learning about culture and presented illustrations of culture associated behaviors, attitudes, assumptions, beliefs and values" had the highest approval grades; as its arithmetic means was (3.98) and its standard deviation was (0.734), while the paragraph, which states "Different peoples with different traditions of thought and culture 
have different and conflicting conceptions of the right and the good" had the lowest approval grades; as its arithmetic means was (3.11) and its standard deviation was (0.898).

Overall, the general average of the arithmetic means for the answers of the respondents is equivalent to (3.56) and the standard deviation is equivalent to (0.807), which indicates the approval of the respondents upon the scale of these paragraphs was Medium, and that their attitudes were positive.

Table 4. Arithmetic means and standard deviations for the members of the study sample answers measuring the attitudes towards the national responsibility perspective

\begin{tabular}{|c|c|c|c|c|c|}
\hline $\mathrm{NO}$ & Statement & A M & S D & Rank & Grade \\
\hline 16 & $\begin{array}{l}\text { Some think it makes no sense to think of nations and other collectives } \\
\text { responsible over the social media networks }\end{array}$ & 3.60 & 0.782 & 3 & Medium \\
\hline 17 & $\begin{array}{l}\text { Different people with different traditions of thought and culture have different } \\
\text { and conflicting conceptions of the right and the good }\end{array}$ & 3.11 & 0.898 & 5 & Medium \\
\hline 18 & $\begin{array}{l}\text { Social media highlighted our international experiences in learning about culture } \\
\text { and with presented illustrations of culture associated behaviors, attitudes, } \\
\text { assumptions, beliefs and values }\end{array}$ & 3.98 & 0.734 & 1 & High \\
\hline 19 & $\begin{array}{l}\text { Their members of social media users subscribe to a common public culture, } \\
\text { despite individual differences in belief and value, and they participate in } \\
\text { mutually beneficial practices whose shape they have a chance to influence }\end{array}$ & 3.23 & 0.845 & 4 & Medium \\
\hline 20 & $\begin{array}{l}\text { When a nation depends on national policies, the members of the nation are } \\
\text { differentially responsible }\end{array}$ & 3.87 & 0.775 & 2 & High \\
\hline & General average & 3.56 & 0.897 & - & Medium \\
\hline
\end{tabular}

(AM) is the arithmetic means, (SD) is the standard deviation

\subsection{Trends Toward Political Awareness}

The political awareness variable is measured in paragraphs (21-30), as illustrated in table (5), and that the arithmetical means for answers of the study sample ranged between (4.04-2.61), and the standard deviations ranged between (1.267-0.775).

All of these arithmetic means show the approval of the study sample on the paragraphs that measure the political awareness variable, since all the arithmetic means are greater than the default means.

Also noted that the paragraph, which states "Social networks provide the chance to express political opinions frankly and freely" had the highest approval grades; as its arithmetic means was (4.04) and its standard deviation was (0.775), while the paragraph, which states "Social network sites contributed in showing the real picture of the political situation" had the lowest approval grades; as its arithmetic means was (2.61) and its standard deviation was (1.267).

Overall, the general average of the arithmetic means for the answers of the respondents is equivalent to (3.33) and the standard deviation is equivalent to (0.933), which indicates the approval of the respondents upon the scale of these paragraphs was Medium, and that their attitudes were positive.

Table 5. Arithmetic means and standard deviations for the members of the study sample answers measuring the attitudes towards political awareness.

\begin{tabular}{llllll}
\hline NO & Statement & A M & S D & Rank & Grade \\
\hline 21 & $\begin{array}{l}\text { Social network sites contributed in showing the real picture of the political } \\
\text { situation }\end{array}$ & 2.61 & 1.267 & 10 & Medium \\
22 & $\begin{array}{l}\text { Social network sites contributed to identify the political situation in societies } \\
23\end{array}$ & 3.71 & 0.811 & 4 & High \\
24 & $\begin{array}{l}\text { Social networks is an important source for information about different issues } \\
\text { Social network sites contributed in demonstrations and revolutions lately }\end{array}$ & 2.78 & 1.221 & 9 & High \\
25 & $\begin{array}{l}\text { Social network sites shorten the distances between different cultures to } \\
\text { understand their political issues }\end{array}$ & 3.43 & 0.875 & 6 & Medium \\
& $\begin{array}{l}\text { Social network sites give the chance to the users to discuss different political } \\
\text { issues with others }\end{array}$ & 2.78 & 1.045 & 8 & Medium
\end{tabular}


27

networks provide the chance to express political opinions frankly and freely

28

Social network sites contributed in attending dialogue issues and acceptance to the other

29

Social network sites encourage the effective sharing with others and dialogues to solve the dominant problems of society

Social network sites became an outlet to express and discuss political issues freely

General average

4.04

$0.775 \quad 1$

High

3.62

$0.8235 \quad$ Medium

3.23

0.8767 Medium

3.87

0.7912 High

3.33

0.933

Medium

(AM) is the arithmetic mean, (SD) is the standard deviation

\section{Testing the Study Hypotheses}

\subsection{Testing the Major Hypothesis}

H0: At the level of significance $(\alpha \leq 0.05)$, there will be no statistically significant differences of the role of social media in developing social responsibility and political awareness of the Jordanian youth.

In order to test the major hypothesis, the sub-hypotheses should be tested as follows:

\subsection{Testing the First Sub-hypothesis}

H01: At the level of significance $(\alpha \leq 0.05)$, there will be no statistically significant differences of the role of social media in developing social responsibility of the Jordanian youth upon gender.

It is noted from simple regression analysis results described in table (6) that there is an effect of the social media in developing social responsibility of the Jordanian youth upon gender.

This statistically significant effect at the statistically significant level $(\alpha=0.05)$, as the calculated $(T)$ value is (7.841), which is higher than tabulated $(\mathrm{T})$ value, is in line with the simple regression analysis results that explain the $(0.197 \%)$ variance in the role of social media in developing social responsibility of the Jordanian youth upon gender.

According to that the null hypothesis (H01) will be rejected and the alternative hypothesis will be accepted, confirming that at the level of significance $(\alpha \leq 0.05)$, there will be a statistically significant differences of the role of social media in developing social responsibility of the Jordanian youth upon gender.

Table 6. Testing results of the first sub- hypothesis

\begin{tabular}{lllll}
\hline Significant $(\mathrm{T})$ & Calculated $(\mathrm{T})$ & Tabulated $(\mathrm{T})$ & $(\mathrm{R})$ Square & $(\mathrm{R})$ \\
\hline 0.001 & 7.841 & 1.960 & 0.197 & 0.444 \\
\hline
\end{tabular}

\subsection{Testing the Second Sub-hypothesis}

H02: At the level of significance $(\alpha \leq 0.05)$, there will be no statistically significant differences of the role of social media in developing political awareness of the Jordanian youth upon gender.

It is noted from simple regression analysis results described in table (7) that there is an effect of the social media in developing political awareness of the Jordanian youth upon gender.

This statistically significant effect at the statistically significant level $(\alpha=0.05)$, as the calculated (T) value is (12.633), which is higher than tabulated (T) value, is in line with the simple regression analysis results that explain the $(39.0 \%)$ variance in in the role of social media in developing political awareness of the Jordanian youth upon gender.

According to that the null hypothesis (H02) will be rejected and the alternative hypothesis will be accepted, that means at the level of significance $(\alpha \leq 0.05)$, there will be a statistically significant differences of the role of social media in developing political awareness of the Jordanian youth upon gender.

Table 7. Testing results of the second sub- hypothesis

\begin{tabular}{ccccc}
\hline Significant $(\mathrm{T})$ & Calculated $(\mathrm{T})$ & Tabulated $(\mathrm{T})$ & $(\mathrm{R})$ Square & $(\mathrm{R})$ \\
\hline 0.002 & 12.633 & 1.960 & 0.390 & 0.624 \\
\hline
\end{tabular}




\subsection{Testing the Third Sub-hypothesis}

H03: At the level of significance $(\alpha \leq 0.05)$, there will be no statistically significant differences of the role of social media in developing social responsibility of the Jordanian youth upon education level.

It is noted from simple regression analysis results described in table (8) that there is an effect of social media in developing social responsibility of the Jordanian youth upon education level.

This statistically significant effect at the statistically significant level $(\alpha=0.05)$, as the calculated $(T)$ value is (11.00), which is higher than tabulated (T) value, is in line with the simple regression analysis results that explain the $(32.64 \%)$ variance in the role of social media in developing social responsibility of the Jordanian youth upon education level.

According to that the null hypothesis (H03) will be rejected and the alternative hypothesis will be accepted, that means at the level of significance $(\alpha \leq 0.05)$, there will be a statistically significant differences of the role of social media in developing social responsibility of the Jordanian youth upon education level.

Table 8. Testing results of the third sub hypothesis

\begin{tabular}{ccccc}
\hline Significant $(\mathrm{T})$ & Calculated $(\mathrm{T})$ & Tabulated $(\mathrm{T})$ & $(\mathrm{R})$ Square & $(\mathrm{R})$ \\
\hline 0.003 & 11.00 & 1.960 & 0.326 & 0.571 \\
\hline
\end{tabular}

\subsection{Testing the Forth Sub-hypothesis}

H04: At the level of significance $(\alpha \leq 0.05)$, there will be no statistically significant differences of the role of social media in developing political awareness of the Jordanian youth upon education level.

It is noted from simple regression analysis results described in table (9) that there is an effect of social media in developing political awareness of the Jordanian youth upon education level.

This statistically significant effect at the statistically significant level $(\alpha=0.05)$, as the calculated (T) value is (17.766), which is higher than tabulated (T) value, is in line with the simple regression analysis results that explain the $(55.80 \%)$ variance in the role of social media in developing political awareness of the Jordanian youth upon education level.

According to that the null hypothesis (H04) will be rejected and the alternative hypothesis will be accepted, that means at the level of significance ( $\alpha \leq 0.05$ ), there will be a statistically significant differences of the role of social media in developing political awareness of the Jordanian youth upon education level.

Table 9. Testing results of the fourth sub- hypothesis

\begin{tabular}{ccccc}
\hline Significant $(\mathrm{T})$ & Calculated $(\mathrm{T})$ & Tabulated $(\mathrm{T})$ & $(\mathrm{R})$ Square & $(\mathrm{R})$ \\
\hline 0.000 & 17.766 & 1.960 & 0.558 & 0.747 \\
\hline
\end{tabular}

\subsection{Testing the Fifth Sub-hypothesis}

H05: At the level of significance $(\alpha \leq 0.05)$, there will be no statistically significant differences of the role of social media in developing social responsibility of the Jordanian youth upon specialization.

It is noted from simple regression analysis results described in table (10) that there is an effect of social media in developing social responsibility of the Jordanian youth upon specialization.

This statistically significant effect at the statistically significant level $(\alpha=0.05)$, as the calculated $(\mathrm{T})$ value is (17.55), which is higher than tabulated $(\mathrm{T})$ value, is in line with the simple regression analysis results that explain the $(55.20 \%)$ variance in the role of social media in developing social responsibility of the Jordanian youth upon specialization.

According to that the null hypothesis (H05) will be rejected and the alternative hypothesis will be accepted, that means at the level of significance $(\alpha \leq 0.05)$, there will be a statistically significant differences of the role of social media in developing social responsibility of the Jordanian youth upon specialization.

Table 10. Testing results of the fifth sub- hypothesis

\begin{tabular}{ccccc}
\hline Significant $(\mathrm{T})$ & Calculated $(\mathrm{T})$ & Tabulated $(\mathrm{T})$ & $(\mathrm{R})$ Square & $(\mathrm{R})$ \\
\hline 0.002 & 17.550 & 1.960 & 0.552 & 0.743 \\
\hline
\end{tabular}




\subsection{Testing the Sixth Sub-hypothesis}

H05: At the level of significance $(\alpha \leq 0.05)$, there will be no statistically significant differences of the role of social media in developing political awareness of the Jordanian youth upon specialization.

It is noted from simple regression analysis results described in table (11) that there is an effect of social media in developing political awareness of the Jordanian youth upon specialization.

This statistically significant effect at the statistically significant level $(\alpha=0.05)$, as the calculated $(\mathrm{T})$ value is (19.647), which is higher than tabulated (T) value, is in line with the simple regression analysis results that explain the $(60.70 \%)$ variance in the role of social media in developing political awareness of the Jordanian youth upon specialization.

According to that the null hypothesis (H06) will be rejected and the alternative hypothesis will be accepted, that means at the level of significance $(\alpha \leq 0.05)$, there will be a statistically significant differences of the role of social media in developing political awareness of the Jordanian youth upon specialization.

Table 11. Testing results of the sixth sub- hypothesis

\begin{tabular}{ccccc}
\hline Significant $(\mathrm{T})$ & Calculated $(\mathrm{T})$ & Tabulated $(\mathrm{T})$ & $(\mathrm{R})$ Square & $(\mathrm{R})$ \\
\hline 0.000 & 19.647 & 1.960 & 0.607 & 0.779 \\
\hline
\end{tabular}

\section{Recommendations}

In light of the findings of the study results and discussion, the researcher recommends the following:

1. Carrying out similar studies on different societies, to examine the impact of the use of social media in the development of social responsibility.

2. Spreading the awareness among young people about the role and impact of social media in developing their personalities and guiding them to optimize the use of social media in a social responsible context.

3. Conducting training courses for young people aimed at developing their skills in applying social media in the service of their social issues serving their nation, especially in the field of advocacy and pressure.

\section{References}

Abu Yaqub, S. Y. (2015). The Impact of Social media on Political Awareness of the Palestinian Cause among An-Najah University Students (Unpublished Master Thesis). An-Najah University, Palestine.

Al-Sabbagh, A. (2010). Means of Communication and Modern Technology. Journal of Technological Sciences, (8). Petra University, Amman. Jordan.

Al-Shahri, F. B. A. (2009). Social Network Sites are No Longer for Adolescents. Ar-Riyadh Paper, No.14776 December.

Al-Sharhan, J. A. A. (2003). Educational Aids and Latest Teaching Technologies (3rd ed.). Riyadh, Al-Humaidi Printing Press.

Aren, K. (2010). Facebook and the technology revolution. N.Y. Spectrum Publications.

Awad, H. (2015). The Impact of Social media on the Development of Social Responsibility among Young People (Unpublished Master Thesis). Al-Quds Open University.

Ben Wargla, N. (2015). The Role of Social Networks in Developing Political and Social Awareness among Arab Youth (Unpublished Master Thesis). University of Djelfa, Algeria.

Butts, C. (2012). Social Media's role in Communication and globalization: A case study of local perceptions on a global scale. Final Project, North Carolina State University, Com 521: Communication \& Globalization.

Castells, M. (2011). The rise of the network society: The information age: Economy, society, and culture (Vol. 1). John Wiley \& Sons.

Collins, A., \& Halverson, R. (2010). The second educational revolution: Rethinking education in the age of technology. Journal of computer assisted learning, 26(1), 18-27. https://doi.org/10.1111/j.1365-2729.2009.00339.x

Dyrly, O., \& Kinnman, H. (1996). Energizing the Classroom Curriculum through Telecommunications. Technology and Learning, 16. 
Ghazal, M. (2014). The Effect of Social media on the Development of Political Awareness among University Students (Unpublished Master Thesis). Qasidi University.

Göksu, N. F. (2014). Point of View to Social Responsibility Understanding from Social Media (Facebook $\begin{array}{lllll}\text { Sample). Procedia-Social and Behavioral } & \text { Sciences, }\end{array}$ https://doi.org/10.1016/j.sbspro.2014.10.293

Golbeck, J. A. (2005). Computing and applying trust in web-based social networks (Doctoral dissertation).

Hart, S. M. (2008). The design decisions of teachers during technology integration (Doctoral dissertation, Wayne State University).

Holmes, K. M., \& O'loughlin, N. (2014). The experiences of people with learning disabilities on social networking sites. British Journal of Learning Disabilities, 42(1), 1-5. https://doi.org/10.1111/bld.12001

Husein, A. H. M. A., Al-Sukkar, A. S., Salah, A. A. A., \& Jaradat, A. A. (2013). The Impact of Social Network Sites to Determine Students Orientations: Field Study on Jordanian Private Universities.

Ibrahim, E. (2009). The Effect of Facebook on the Behavior of University Students (Unpublished Master Thesis). Faculty of Education, Ain Shams University, Cairo.

Köseoğlu \& Köker, N. E. (2014). Türk universiteleri Twıtter’ı diyalogsal iletişim açısından nasıl kullanıyor: Beş türk universitesi uzerine bir içerik analizi. Global Media Journal, 4(8).

Laker, A. (2002). Beyond the boundaries of physical education: Educating young people for citizenship and social responsibility. Routledge.

Maguth, B. M. (Ed.). (2013). New directions in social education research: The influence of technology and globalization on the lives of students. IAP.

Molaei, H. (2014). The prospect of civility in Indonesians' online polarized political discussions. Asian Journal of Communication, 24(5), 490-504. https://doi.org/10.1080/01292986.2014.917116

Molaei, H. (2017). Social Media and Politics: Examining Indonesians' Political Knowledge on Facebook. Journal of Cyberspace Policy Studies, 1(1), 119-139.

Yigit, F. \& Tarman, B. (2013). The Impact of Social Media on Globalization, Democratization and Participative Citizenship. Journal of Social Science Education, 12(1), 75-80.

Zeitel-Bank, N., \& Tat, U. (2014). Social Media and Its Effects on Individuals and Social Systems. In Human Capital without Borders: Knowledge and Learning for Quality of Life; Proceedings of the Management, Knowledge and Learning International Conference 2014 (pp. 1183-1190). ToKnow Press.

\section{Copyrights}

Copyright for this article is retained by the author(s), with first publication rights granted to the journal.

This is an open-access article distributed under the terms and conditions of the Creative Commons Attribution license (http://creativecommons.org/licenses/by/4.0/). 